\title{
Geospatial Crypto Reconnaissance: A Campus Self-Discovery Game
}

\author{
Harjinder Singh Lallie \\ University of Warwick (WMG), Coventry, UK
}

\author{
h.s.lallie@warwick.ac.uk
}

\begin{abstract}
Campus discovery is an important feature of a university student induction process. Approaches towards campus discovery differ from course to course and can comprise guided tours that are often lengthy and uninspiring, or self-guided tours that run the risk of students failing to complete them. This paper describes a campus self-discovery induction game (Geospatial Crypto Reconnaissance) which aims to make students aware of campus resources and facilities, whilst at the same time allowing students to make friends and complete the game in an enthusing and exciting way.

In this paper we describe the game construct, which comprises of a location, message, and artefact, and also the gameplay. Geospatial Crypto Reconnaissance requires students to identify a series of photographs from around the campus, to capture the GPS coordinates of the location of the photograph, to decipher a ciphered message and then to return both the GPS coordinates and the message for each photograph, proving that the student has attended the location. The game had a very high satisfaction score and we present an analysis of student feedback on the game and also provide guidance on how the game can be adopted for less technical cohorts of students.
\end{abstract}

Keywords: Integration; orientation; retention; campus discovery; induction games; induction

\section{Introduction}

Universities, colleges and other higher education institutions - collectively referred to herein as universities - conduct an induction program, also known as orientation or registration week, for new students at the first year of their studies at Bachelors, Masters and other levels of study. Throughout this paper, we use the term induction to refer to the induction program and course to refer to a university program of studies such as a BSc or MSc.

Induction is a key part of the student academic experience, so vital says Tinto (1993) that one of the reasons for student withdrawal in the first six months of a university course is quite often re-

Material published as part of this publication, either on-line or in print, is copyrighted by the Informing Science Institute. Permission to make digital or paper copy of part or all of these works for personal or classroom use is granted without fee provided that the copies are not made or distributed for profit or commercial advantage AND that copies 1) bear this notice in full and 2) give the full citation on the first page. It is permissible to abstract these works so long as credit is given. To copy in all other cases or to republish or to post on a server or to redistribute to lists requires specific permission and payment of a fee. Contact Publisher@InformingScience.org to request redistribution permission. lated to the failure of a student to integrate into their university - as well as the student's own prior experiences (Tinto, 1993). These views were supported by Yorke and Longden (2008) who contend that the proactive management of the student transition into higher education is a key factor in the retention of students. Whilst there appears to be general agreement that well managed, cohesive and robust induction 
processes have a positive effect on retention and subsequent student experiences, it appears that no study to date has provided empirical evidence to demonstrate this.

Cook (2006) contends that universities are excellent at preparing students for professional life, but not as good at preparing them for academic life. Often the amount of information presented to students during induction can be quite overwhelming (Cook, 2006), and the process has occasionally been criticised for being confusing and 'overly bureaucratic' (Harvey \& Drew, 2006; Lewis, 1984). This is evidenced in the amount of information that students get during induction, which is often supported with a range of hand-outs, such as contact lists, business cards, DVDs, USB memory sticks, booklets and paper hand-outs.

Given the importance of managing the transition experience of a student, the process of induction requires more consideration and research than has hitherto been given and academics must explore more enthusing and exciting methods to make induction more fun and in particular more memorable for students.

There is already a range of literature which focuses on the induction experience as shown by Harvey and Drew (2006) but what seems apparent is that there is a dearth of literature focussing specifically on campus discovery. That is the focus of the present paper which explores the issue of campus self-discovery and outlines a game played during the induction week at the University of Warwick by students on the MSc Cyber Security and Management degree.

We believe that embodied and distinctive experiences are more conducive to student learning and engagement with that learning; therefore, we aimed to make the experience of this game particularly distinctive. The purpose of the game was to encourage the students to self-discover the campus in small groups, to do so in a fun way and to get to know some of their colleagues in the process.

\section{Induction}

Induction is a key process which aids in managing two elements of the student transition into higher education: separation from the student's previous educational experience and environment, and transition and incorporation/integration into the new environment (Tinto, 1987).

Induction typically fulfils four goals related to the integration/incorporation of students into the university environment. Induction aims to: develop resource and support awareness; develop academic regulatory awareness; develop geographic campus awareness; and aid in achieving social integration.

a. Resource and support awareness. This includes creating an awareness of the services offered by library facilities, support services, resources, eateries, cafes, sports facilities and the various student clubs and societies.

b. Academic regulatory awareness. This introduces students to the structure of the course, assessment criteria, attendance requirements, health and safety regulations, academic rules and in particular the regulatory framework that governs the progress of students on their chosen program of studies. During this process, students register and enrol in their course.

c. Campus awareness. It is particularly important that students become familiar with the geography of the campus and, in particular, key locations, amenities and study spaces.

d. Social integration. Given the diverse student demography and ability range entering higher education today, a higher number of students find it difficult to integrate - many of whom begin to feel socially isolated (McLaughlin, Southall, \& Rushton, 2006); this has been cited as an important factor contributing to the non-completion of studies (Yorke \& Longden, 2008). A key aspect of induction therefore is to aid the social integration of students into 
the university, the chosen course and, importantly, the student cohort. This is usually achieved through 'ice breaker' activities designed to allow students to become familiar with their colleagues on the university course as well as beyond it across the university.

The structure of induction varies from course to course and can range from a one week intensive program at the beginning of studies, to longitudinal programs involving on-going sessions and activities that take place over the first few weeks and occasionally over the whole of the first year.

The induction program comprises a series of events and activities, some of which are offered as pre-entry events before the majority of students arrive on campus. These events often comprise of residential field trips, days out, ice-breaker sessions, campus tours and talks from course leaders, departmental heads, heads of support services and student unions.

The program is occasionally tailored towards particular groups of students; for instance, universities are aware that international students often require specialist assistance to help them integrate into both the country and the university. Similarly, students living in non-university accommodation, require specialist support. Students in this position find it more difficult to integrate well with other students in the cohort or across the university, particularly as campus/university accommodation based students tend to spend more time together studying as well as socialising (Lowe \& Cook, 2003). This is borne out in a study by Yorke and Longden (2008) who find that students in such a position also cite financial problems, a lack of personal support from family, the demands of employment, travel difficulties, the quality and suitability of the teaching, and the amount of contact with academic staff, as contributory reasons for their non-completion.

\section{Geospatial Crypto Reconnaissance}

The University of Warwick occupies more than 720 acres of campus space on a single site. It offers a campus experience to students wherein the teaching facilities, student accommodation, a range of shops, restaurants, a cinema, theatre, music centre and sports facilities are all contained within the campus. The campus is often referred to as the 'bubble' as students rarely need to leave the campus.

As with many campuses, students feel quite overwhelmed when they arrive for the beginning of their studies and occasionally undergo a culture shock, often because their prior study experience is based around a much smaller campus where the resources/facilities are more closely located.

It is quite common for the student experience of lectures, tutorials and other academic engagements at the University of Warwick, to spread across the length and breadth of the campus during the time of their studies. Students often have to travel as much as twenty minutes between classes and it is therefore doubly important that students become aware of the geography of the campus quickly and at an early stage, as otherwise it can involve a series of late appearances to taught sessions in the early part of their studies.

Whilst the game in this case study was played on a large campus, the game can be adapted for smaller campuses as well as campuses spread across a city. The game play limits are that students should be able to reach an adequate number of location points, as discussed later, so as to score adequate points within the time constraints given in the task.

Traditional approaches to campus discovery typically involve guided tours led by academics or student ambassadors/representatives. During the tour, key locations in the campus are introduced in anticipation that students will remember the series of locations briefly highlighted during what may be a very busy tour. The alternative to guided tours are self-discovery tours where students are given a detailed itinerary which they must follow and complete on their own or as a group. Occasionally, self-discovery tours are constructed as treasure trails (Queen's University Belfast, 2013; University of Bath, 2013), where students visit key parts of the campus collecting 'arte- 
facts' which evidence their attendance at those points. However, with most self-discovery events, there is a risk that students may lack the motivation to undertake the tour and quite often such a tour remains uncompleted.

For these reasons, the course leader of the MSc Cyber Security and Management course was motivated to develop a self-discovery game which would enthuse and excite the students and, in particular, inspire them to complete the game and thereby discover important parts of the campus. The feedback from students undergoing the tour was very positive and the game is presently being developed to suit the requirements of other courses/departments around the university.

It should be noted that the previous experience of campus discovery was deemed satisfactory by the course team. The motivation behind the present case study was to enhance the campus discovery experience. There is no control data with which the experiential feedback from this case study can be compared.

\section{Game Play, Construct and Ludology}

Most good games are developed with a sound understanding of the game audience and their motivation levels. In the present example, the audience comprised of the full time student cohort on the MSc Cyber Security and Management program at WMG (Warwick Manufacturing Group, University of Warwick). This comprised of $28 \mathrm{MSc}$ students from 14 countries. Four students were UK nationals who had previously been through a bachelors program in the UK. Four students came from the EU and the remaining 19 students came from outside the UK/EU. All students enter the course with a strong computing background, generally having studied computer science, information systems or (exceptionally) business information systems/business information technology.

Six students had arrived on campus two weeks before the induction week and had participated in an international orientation week which prepares them for university study. This is a service offered in addition to the normal induction and is designed to help students adapt to UK study and to understand UK culture.

Before proceeding to describe the game play, construct and ludology, it is worth spending a moment reflecting on game design theories. Gee (2005, p.23) defines a game as "a set of experiences a player participates in from a particular perspective". Prensky (2005) adds to this by defining five levels of learning achieved in a good game as the how, what, why, where, and when/whether. These are described more fully as:

- How - Players learn how to do things, particularly where real life situations are simulated in the game.

- What - What are the constraints and limits in a real life scenario which the game is intended to replicate?

- Why - Why does one take particular actions in a real life scenario and therefore how can this be replicated in a game scenario?

- Where - This refers to the context of a game and as Prensky (2005, p.107) puts it, understanding "the world of the game and the values it represents".

- When and whether - This refers to the process of contextualising decision making, the consideration of possible decisions, and the determination of when to make a particular decision.

Whilst Prensky's ideas focus on digital game design, the theory applies equally to classroom games. We add to some of this theory by positing that effective classroom games must comprise a 
number elements, two of which are that it should be challenging and must have a goal. The challenge in a game is often achieved by limiting the time available to complete the game, scoring points, by competing against other game players, and/or by adding adequate complexity - which, in the case of digital games, increases at each level of achievement.

The self-discovery game in the present discussion is a non-digital serious game that comprises of three fundamental constructs (or content as Gee (2005) refers to it): location, message and artefact:

i. Location. This comprises of a set of locations that are considered important to the student's experience at the campus.

ii. Message. A message that imparts information, such as a description of the location, the services available and other important information about the location and possibly about other locations.

iii. Artefact. This comprises of an item that the student must collect to prove that he/she attended the location; in the present example, this is the pair of GPS coordinates.

The game requires students to identify a series of photographs, to capture the GPS coordinates of the location of the photographs (to prove student attendance at the location), decrypt an encrypted message, and to return both the GPS coordinates and the deciphered messages to the course leader.

The game was made more challenging and competitive by introducing location and message points. Location points are awarded for each coordinate returned correctly to within 5 metres of the photograph location. Location points range between 1 and 3 depending on the difficulty in identifying the location. Message points are awarded for each correctly deciphered message. Message points range between 1 and 5 where 5 points are awarded for messages that are more difficult to decipher.

Students were required to work in groups of four. One team member must submit the artefacts for the whole group, but all members of the group have to complete a survey providing feedback on the game. Whilst we felt that the game play would be exciting enough to encourage student participation, it was felt that students needed to be further incentivised to complete the game so three further incentives were provided. On submission of the artefacts and the completion of the survey, all group members were given a one year full subscription to a popular anti-virus program, added to the course Facebook page and given a case study necessary for the first module of study.

\section{Location and Artefact}

Eighty nine photographs were collected widely from around the campus from locations that the course leader felt were important to the student experience. Examples of these included the student union, the central administration department, cafes, halls of residences, restaurants, learning centres and signposts to counselling services.

The photographs were collected on an iPhone $4 \mathrm{~S}$ with the location services facility enabled so as to automatically collect GPS coordinates. Whilst there are no costs associated with the development of the game, there is an assumption that the user has a phone or camera which can take photos which capture GPS data.

For the game to work, the coordinates must be accurate - particularly as we need to compare student submitted coordinates against the original coordinates. GPS receivers are prone to inaccuracy problems and this results occasionally in captured GPS coordinates being inaccurate (Strawn, 
2009). A number of solutions have been proposed to deal with this, one of which involves the use of Wi-Fi technology to enable better accuracy and another involves the use of Assisted GPS (AGPS) (Djuknic \& Richton, 2001). However, we did not have any of these technologies available because GPS data capture took place outside of any Wi-Fi range.

For these reasons, we needed to validate the accuracy of each captured set of GPS coordinates. To do this, GPS coordinates were plotted using TagView Evigator (Evigator Digital Forensics, 2011), each coordinate was plotted and then zoomed in to see how close the plotted location was to the original captured set of coordinates (Figure 1). Through this process we found that a number of the coordinates returned by the iPhone GPS system were inaccurate; in one case, by as much as 7 meters. This was addressed by revisiting the location and taking a new set of coordinates using a Samsung Galaxy phone. Through this process a set of accurate coordinates were achieved.

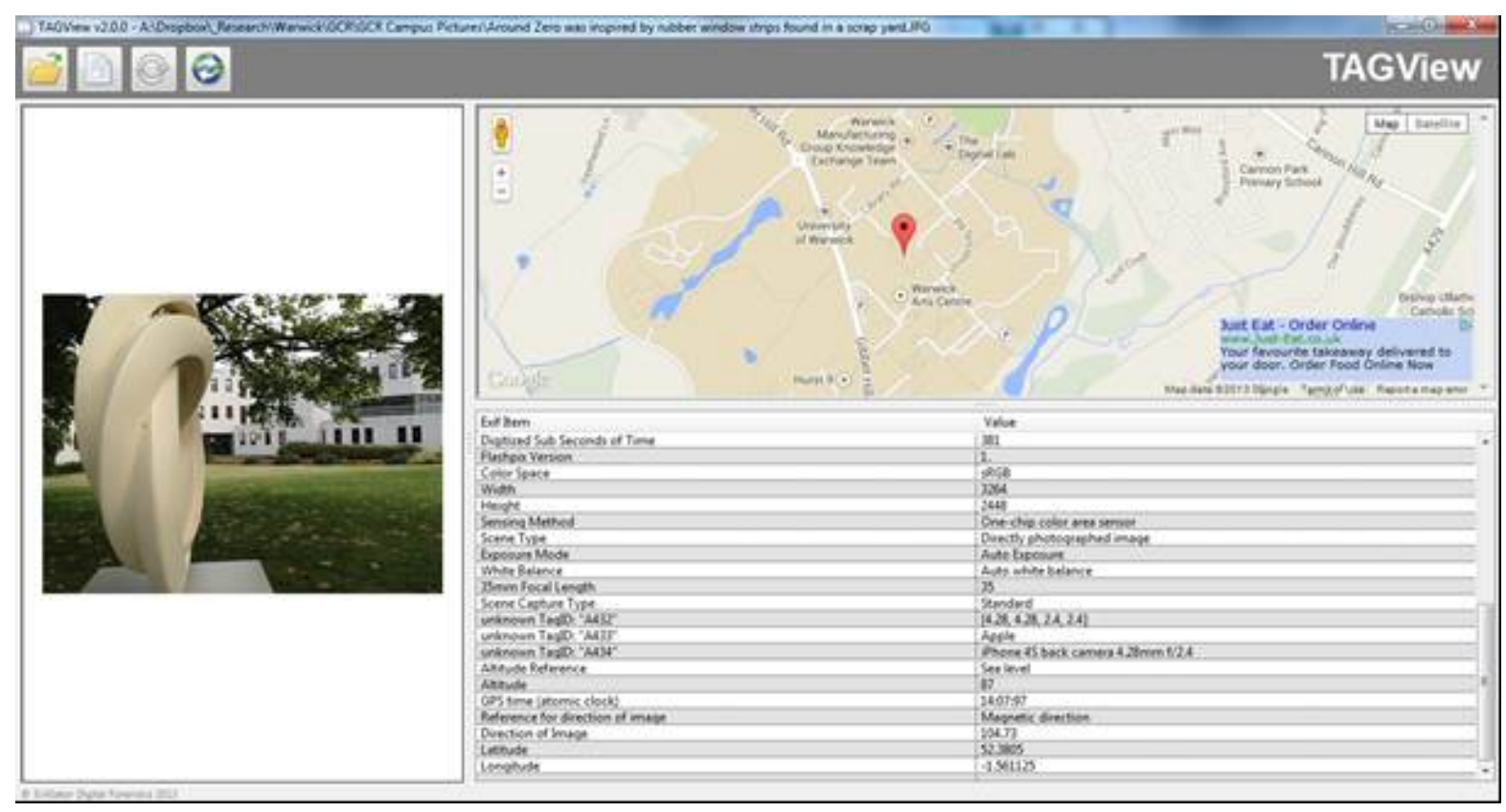

Figure 1: TagView Evigator (Evigator Digital Forensics, 2011)

\section{The Message}

Each photograph was paired with a message that typically describes the location. The message, which we refer to as plain-text, was encrypted to produce a cipher-text and this cipher-text was provided to students. A number of simple cipher systems were used to convert the plain-text to cipher-text. One of the more simple systems is the 'Caesar substitution cipher' where each character in a message is substituted for another character. In other cases the method of encrypting the plain text was somewhat more elaborate but easily solved nevertheless; for instance, the following cipher:

\section{KMHESU FG KWUSDH WWXXGU QFSE WZL XG WFG VFMGJYCUST WZL FA, WJSMIK KWUFWAUK DSAUGK WZL QT WJMLHDMUK S}

Corresponds to the following text:

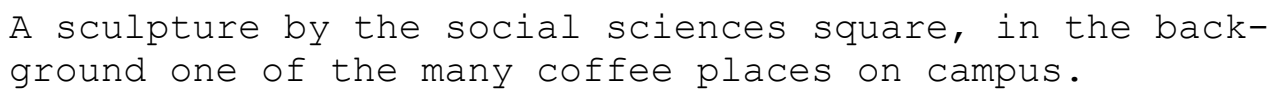


In this example, the text has been reversed to produce the following:

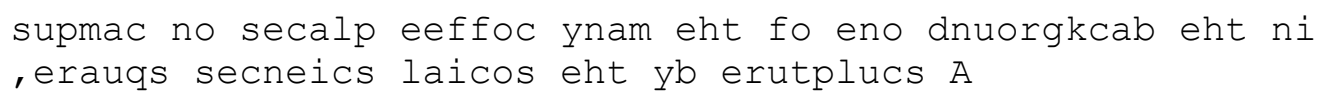

and then Caesar Ciphered. To solve this the student would apply the Caesar cipher to the message and then reverse the result.

\section{Outcome and Student Strategy}

Thirty five photographs were provided to students as printouts. The photographs were of locations reasonably spread across the campus (Figure 2). Students were given a day and a half to complete the challenge. In future implementations, we may consider reducing this time to 2 or 3 hours so as to make the experience more challenging; nevertheless, a day and a half allowed students to complete the challenge in a leisurely manner.

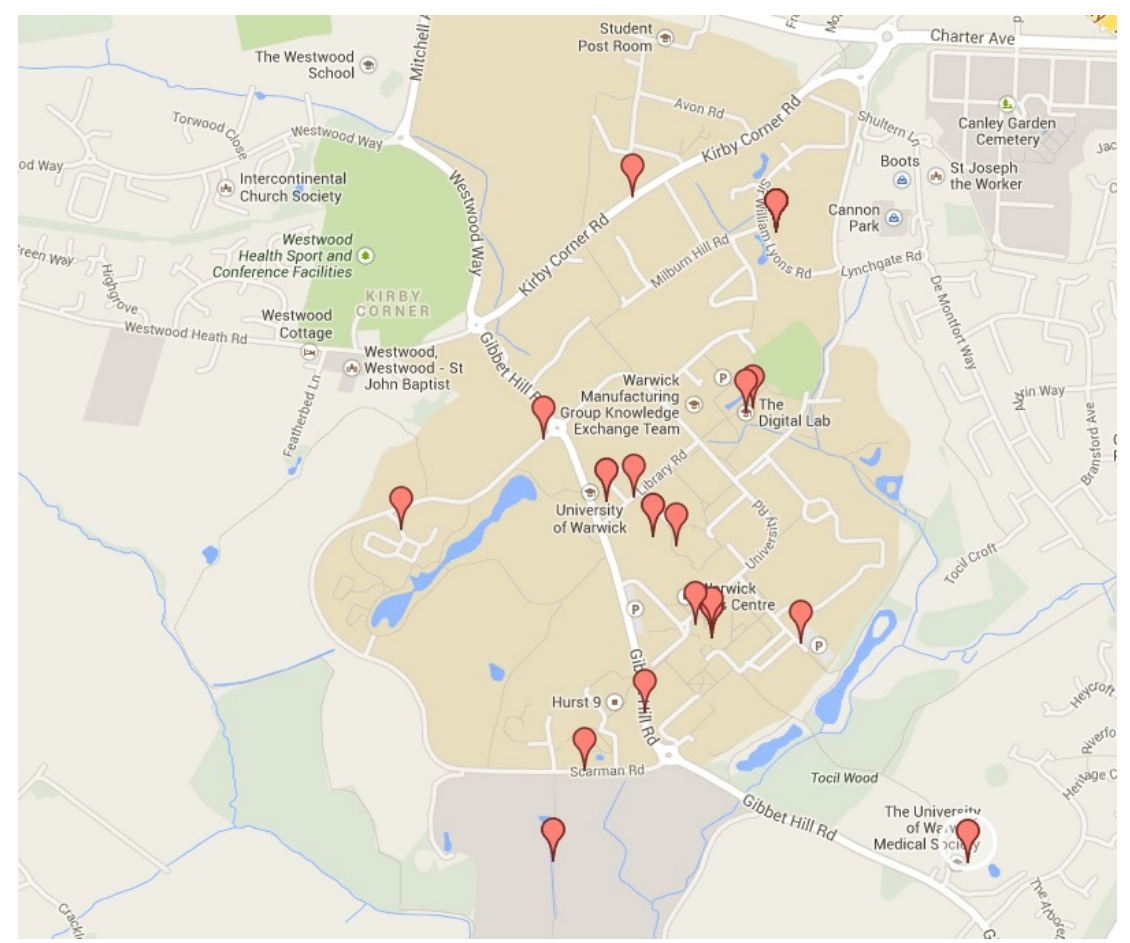

Figure 2: The range of plotted photographs

Students were encouraged to use apps such as FreeGPS, which allows a user to capture the GPS coordinates of the present position (CodeBurners, 2013). Furthermore, they were pointed to three websites that could help in the game: Simon Singh's Cryptography page, which helps in encrypting and decrypting text (Singh, 2014); Jeff Boulter's GPS page, which aids in converting GPS coordinates (Boulter, 2014); and TextMechanic.com, which aids in manipulating text and converting text to various formats (TextMechanic, 2014).

Jeff Boulter's page was important because there are at least four formats for the recording of GPS data: Decimal Degrees; Degrees, Minutes and Seconds; GPS format; and UTM. Students were required to return the coordinates using the DMS format. Jeff Boulter's tool automates the conversion process so, for instance, the Decimal Degrees coordinates 52.3821972222, 1.5555555556 can be converted into the DMS format, which becomes N52 2255 W1 3320. 
Students were asked to capture the coordinates of each photo and to decipher the accompanying messages. The results from each group were uploaded to an online system which captured each set of coordinates and also elicited feedback. The feedback was captured in a comments box allowing students to provide open textual feedback regarding the experience. This allowed the course leader to understand the strategy adopted by students to complete the challenge and also to determine whether the students had achieved the objectives. Five of the students did not have access to the online submission system and were encouraged instead to complete a paper-based feedback form.

From the feedback, we learnt that groups adopted one or a combination of three strategies:

- Random walking. Groups wandered almost aimlessly around campus to discover the locations.

- Intelligence driven. Students who had been through international orientation were aware of some of the locations; they were able to identify these relatively easily. The group therefore needed to focus their efforts on identifying the remaining locations.

- Skill coordination. One group allocated a member to decipher the codes whilst other members of the same group identified the locations.

\section{Analysis and Conclusions}

The results from the game were very encouraging and suggest that we achieved our goal of taking students through a self-discovery campus tour in a fun and enthusing way. All students completed the game. Twenty-five of the 28 students either agreed or strongly agreed that the game was 'exciting and fun', 26 agreed or strongly agreed that the game allowed the student to 'learn about important places on the campus in a fun way'. All 28 students agreed or strongly agreed that the game allowed them to 'make friends and get to know some of my colleagues in a fun/friendly way'.

Twenty-two students agreed or strongly agreed that the game was 'challenging but not overly complicated'. The one area of the game that resulted in a wider-ranging response was the question of whether the game 'took the right amount of time to complete'. Here, 14 agreed or strongly agreed whilst 12 disagreed or strongly disagreed (with two neutral responses). We did not explore this further but one reason for this may have been that by allowing the students to complete the task over a day and a half, we may in fact have had an adverse effect wherein some students felt the game actually took too long.

The open feedback from students was useful and provided useful ideas to improve the game. Some suggested that 'a clue near the real environment of the picture could be very helpful; for example a sign or a quote near a statue'. One student suggested a form of 'Reverse Geospatial Crypto Reconnaissance' wherein we provide the coordinates and a description of the location and the students return a photo of members of the group at the location.

A common complaint was that the GPS application they used was prone to inaccuracies. This was noticed when the coordinates were plotted onto a map and then compared with their physical location. However, in our view, this was part of the challenge and experience and demonstrated to students that they must not rely on a single source of data or information; furthermore, that any tools they use may need to be validated. An alternative may be, as a student suggested, to increase the distance 'to 10/15m instead of $5 \mathrm{~m}$ as accuracy of GPS can be limited'. This would most probably compensate for the inaccuracies as none of the coordinates in our personal test was more than 5 meters away from the target. 
This game in its present format is entirely suitable for students on technical degrees, less so for students on humanities/arts related or other non-technical degree programs. In such a context, students need more detailed guidance such as how to use a GPS app to capture GPS data and how to convert formats (if that is important). The use of a ciphered message may be less suitable for such student groups; instead, a 'Reverse Geospatial Crypto Reconnaissance' game may be more appropriate.

Another area for future development is the development of a seamless application which manages the upload of photographs, extraction of GPS coordinates and the auto-grading of submissions. The package may also manage a leader board to provide a continual update of performance.

\section{References}

Boulter, J. (2014). GPS coordinate converter, maps and info. Retrieved January 12, 2014, from http://boulter.com/gps/

CodeBurners. (2013). Free GPS. Retrieved November 13, 2013, from http://www.codeburners.com/codeburners/freepgs/index.html

Cook, A. (2006). Induction: A formal initiation into a position or office. In A. Cook, K. A. Macintosh, \& B. S. Rushton (Eds.), Supporting students: Early induction (pp.7-12). Coleraine: University of Ulster.

Djuknic, G. M., \& Richton, R. E. (2001). Geolocation and assisted GPS. Computer, 34(2), 123-125. doi: $10.1109 / 2.901174$

Evigator Digital Forensics. (2011). TagExaminer. Retrieved September 28, 2011, from http://www.evigator.com/tag-examiner/

Gee, J. P. (2005). Good video games and good learning. Phi Kappa Phi Forum, 85(2), 33-37.

Harvey, L., \& Drew, S. (2006). The first-year experience: Briefing on induction. Retrieved September 24, 2011, at http://www. heacademy. ac. uk/assets/documents/archive/web0575_the_first_year_experience_briefing_on_induction.pdf

Lewis, I. (1984). The student experience of higher education. London: Croom Helm.

Lowe, H., \& Cook, A. (2003). Mind the Gap: Are students prepared for higher education? Journal of Further and Higher Education, 27(1), 53-76.

McLaughlin, S., Southall, D., \& Rushton, B. S. (2006). Residential events for induction. In A. Cook, K. A. Macintosh, \& B. S. Rushton (Eds.), Supporting students: Early induction (pp. 27-41). Coleraine: University of Ulster.

Prensky, M. (2005). Computer games and learning: Digital game-based learning. Handbook of Computer Game Studies, 18, 97-122.

Queen's University Belfast. (2013). Treasure hunt answers. Retrieved November 24, 2013, from http://www.qub.ac.uk/schools/psy/StudyingAtTheSchool/UndergraduateStudies/Induction/answers/

Singh, S. (2014). Cryptography. Retrieved January 12, 2014, from http://simonsingh.net/cryptography/

Strawn, C. (2009). Expanding the potential for GPS evidence acquisition. Small Scale Digital Device forensics Journal, 3(1), 12.

TextMechanic. (2014). TextMechanic.com. Retrieved 12th January, 2014, 2014, from http://textmechanic.com/

Tinto, V. (1987). Leaving college: Rethinking the causes and cures of student attrition. Chicago, IL: University of Chicago Press.

Tinto, V. (1993). Leaving college: Rethinking the causes and cures of student attrition ( $2^{\text {nd }}$ ed.). Chicago, IL: University of Chicago Press. 
University of Bath. (2013). Maths/Physics induction. Retrieved November 24, 2013, from http://www.bath.ac.uk/new-ug/induction/departments/department-timetables-welcome/physics.html

Yorke, M., \& Longden, B. (2008). The first-year experience of higher education in the UK: Final report. York, UK: The Higher Education Academy. Retrieved September 2, 2010, from http://www. heacademy.ac.uk/assets/York/documents/resources/publications/FYEFinalReport.pdf

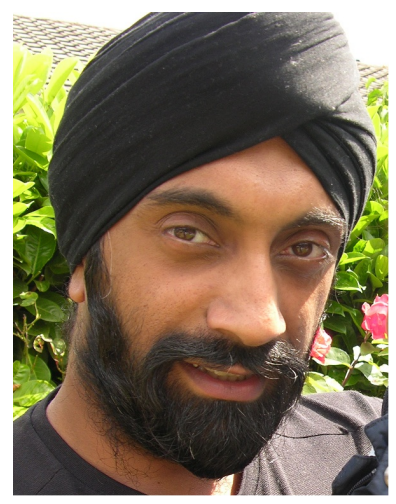

\section{Biography}

Harjinder Singh Lallie (BSc, MSc, MPhil) is a senior teaching fellow in Cybersecurity at the University of Warwick (WMG). He teaches three modules on the program. He has developed and led a number of very successful university courses in Digital Forensics and Security at both undergraduate and postgraduate level.

His research focus is in the area of Digital Forensics and Information Security particularly focussing on social network analysis and is currently studying towards his $\mathrm{PhD}$. He has published dozens of papers in the digital forensics/information security domain and has presented at numerous conferences/workshops. He has held a number of conference committee memberships and acts as an external examiner for three universities. Harjinder is a respected academic in the area of Teaching, Learning, Assessment and Curriculum (TLAC) and regularly organises and delivers at workshops and conferences in this domain. 